\title{
Carcinoma basoescamoso avançado de órbita: relato de caso
}

\author{
An advanced case of basosquamous carcinoma of the orbit: case report
}

\author{
Huber Martins Vasconcelos Jr. ${ }^{1}$ \\ Ana Laura Almeida ${ }^{2}$ \\ AntônioSagawa ${ }^{3}$ \\ Roberto Murillo Limongi de Souza Carvalho ${ }^{4}$ \\ Marcos Pereira de Ávila ${ }^{5}$
}

Trabalho realizado no Departamento de Cirurgia Plástica Ocular do Centro de Referência em Oftalmologia do Hospital das Clínicas do Estado de Goiás - CEROF/ HC - Goiânia (GO) - Brasil.

${ }^{1}$ Acadêmico de Medicina da Faculdade de Medicina da Universidade Federal de Goiás - UFG - Goiânia (GO) - Brasil.

${ }^{2}$ Médica Assistente do Setor de Plástica Ocular do Centro de Referência em Oftalmologia - CEROF, da UFG Goiânia (GO) - Brasil.

${ }^{3}$ Médico Assistente do Setor de Plástica Ocular do CEROF, da UFG - Goiânia (GO) - Brasil.

${ }^{4}$ Chefe do Setor de Cirurgia Plástica Ocular do Centro de Referência em Oftalmologia-CEROF, da UFG - Goiânia (GO) - Brasil.

${ }_{5}^{5}$ Professor, Doutor e Chefe do Serviço de Oftalmologia da Faculdade de Medicina da UFG e Chefe do CEROF, da UFG - Goiânia (GO) - Brasil.

Endereço para correspondência: Roberto Murillo Limongi de Souza Carvalho. Av. T-47 q31 L3/5 - Ed. Monte Carlo - Apto. 1.102 - Setor Bueno - Goiânia (GO) CEP 74210-180

E-mail: rmurillousp@hotmail.com

Recebido para publicação em 15.05.2007

Última versão recebida em 15.06.2009

Aprovação em 29.09.2009

Nota Editorial: Depois de concluída a análise do artigo sob sigilo editorial e com a anuência da Dra. Martha Maria Motono Chojniak e do Dr. Eduardo Ferrari Marback sobre a divulgação de seus nomes como revisores, agradecemos sua participação neste processo.

\section{RESUMO}

Carcinoma basoescamoso é um tumor raro com características de tumor de células basais e escamosas interligados por uma área de transição. Tem sido descrito como um tumor agressivo com possibilidade de metástases à distância, o que difere substancialmente do carcinoma basocelular. Propomos neste relato a descrição de um caso de evolução crônica e das consequências do abandono do tratamento por causa do prognóstico reservado deste tipo de tumor de comportamento agressivo.

Descritores: Carcinoma basocelular; Carcinoma basoescamoso/diagnóstico; Relatos de casos

\section{INTRODUÇÃO}

O carcinoma basocelular, assim como o carcinoma espinocelular apresentam, em geral, comportamento clínico e histopatológico típicos, constituindo entidades nosológicas já bem definidas. No entanto, uma pequena parcela de tumores malignos de origem queratinocítica apresenta características histopatológicas de ambas as neoplasias, simultaneamente, porém com comportamento clínico bem distinto, sendo denominados de carcinomas basoescamosos (CBE) ou metatípicos ${ }^{(1)}$.

O carcinoma basoescamoso (BSC) é um tumor raro com características tanto de carcinoma de células basais quanto de células escamosas unidas por uma área de transição ${ }^{(2)}$. É uma neoplasia epitelial rara com tendência à recorrência local e ao desenvolvimento de metástases à distância, condição que a difere do carcinoma de células basais. Sua incidência varia de 1 a $2 \%$ de todos os carcinomas de pele ${ }^{(3-4)}$.

O diagnóstico baseia-se nos achados histológicos e o tratamento de eleição é a cirurgia com completa ressecção do tumor ${ }^{(4)}$. O comprometimento tumoral da margem cirúrgica apresenta-se como um importante fator prognóstico. Além disso, há uma alta propensão a metástases em linfonodos e à distância que requer um atencioso seguimento pós-tratamento ${ }^{(3)}$. Relataremos abaixo um caso raro de CBE cuja apresentação clínica mostrou destruição dos tecidos orbitários devido à falta de adesão ao tratamento pelo paciente.

\section{RELATO DE CASO}

Paciente do sexo masculino de 50 anos de idade que veio encaminhado ao CEROF com uma história de queimadura química no olho esquerdo (OE) há oito anos. Sua queixa era de dor intensa no OE e deformidade da região periocular. 
Ao exame oftalmológico verificou-se atrofia bulbar à esquerda, sem percepção luminosa, importante simbléfaro, retração de supercílio e moderada secreção mucopurulenta. A ultrassonografia do olho esquerdo revelou espessamento escleral e diminuição do diâmetro axial do globo ocular. Foi então submetido à injeção retrobulbar de álcool para alívio da dor. Durante os próximos cinco meses o paciente relatou recorrência da dor e então foi sugerida a realização de uma evisceração do $\mathrm{OE}$, porém o paciente abandonou o tratamento. Sete meses após, o paciente retornou à nossa instituição apresentando uma lesão ulcerativa na órbita de aspecto infiltrativo (Figura 1). Uma biópsia foi indicada, no entanto o paciente abandonou novamente o tratamento retornando após 20 me-

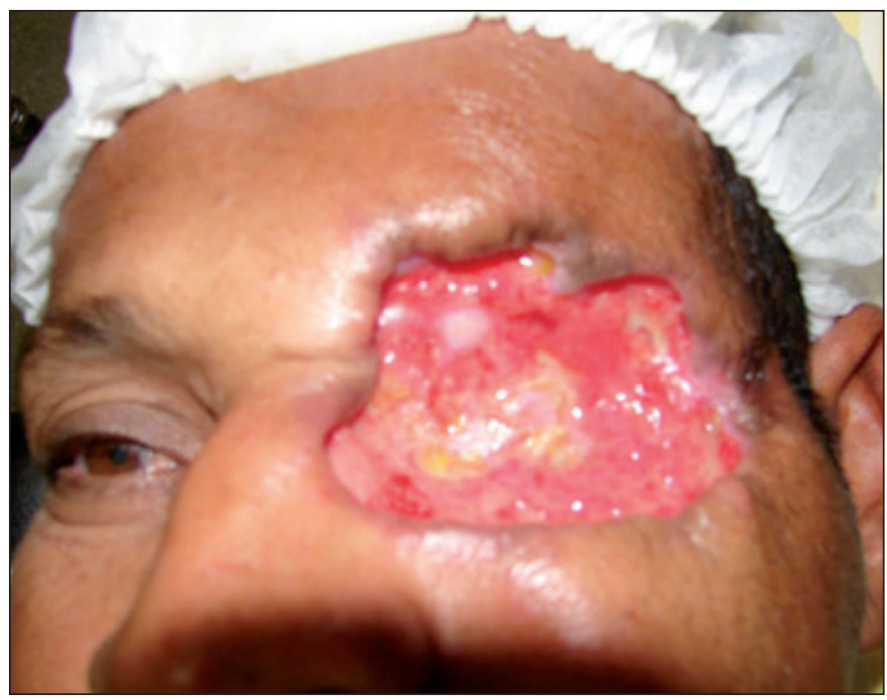

Figura 1 - Lesão ulcerativa de aspecto infiltrativo ses da indicação. Foi então realizada a biópsia que diagnosticou o carcinoma de células basoescamosas e a tomografia computadorizada (TC) de órbita revelou invasão dos tecidos adjacentes.

Foi realizada a exenteração da cavidade orbitária esquerda com ampliação para região periorbitária e facial. Poucos meses após a exenteração o paciente apresentou linfoadenomegalia cervical esquerda e foi referido ao departamento de Cirurgia de Cabeça e Pescoço do Hospital das Clínicas que realizou biópsia do linfonodo que revelou apenas presença de reação inflamatória. Em TC de controle, seis meses após a exenteração, foi verificada invasão de ossos orbitários e o paciente seguiu orientações e considerações do serviço de Cabeça e Pescoço que indicou tratamento complementar com radioterapia.

\section{HISTOLOGIA}

Macroscopia: três fragmentos de tecido de forma irregular de coloração amarronzada de consistência elástica e firme, sendo o de maior medida $6,5 \times 5,0 \times 2,5 \mathrm{~cm}$.

Microscopia: grande lesão neoplásica, ulcerada, infiltrativa com características de carcinoma basoescamoso; blocos de células basais (com pouco citoplasma) que se conectavam com a epiderme. Presença de ceratinização localizada mais reação desmoplásica como visto na figura 2 .

\section{DISCUSSÃO}

O carcinoma basoescamoso é um tumor cutâneo raro, que é pouco descrito na literatura dermatológica. Santos et al. comentam que a existência do CBE foi proposta inicialmente por Darier e Montgomery permanecendo controversa por décadas.
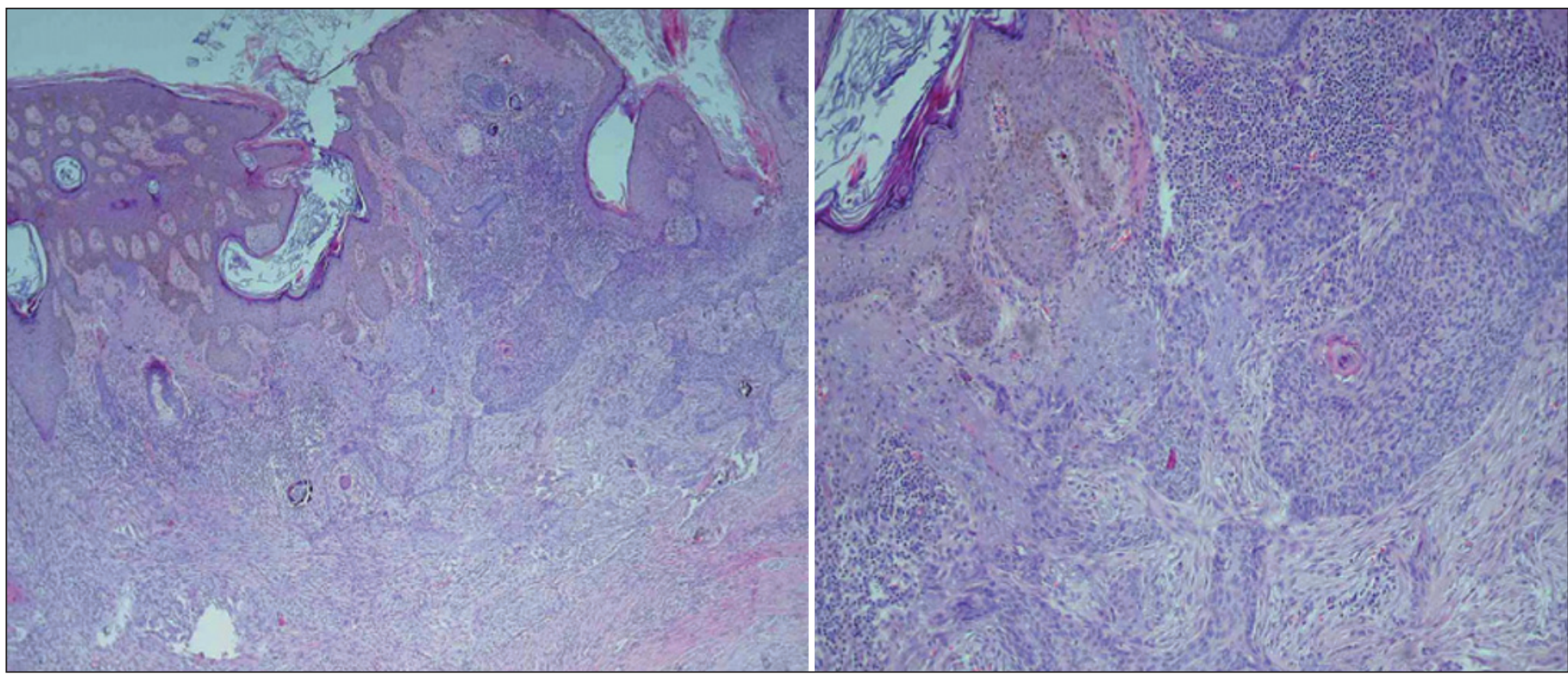

Figura 2 - Blocos de células basalóides e presença de focos de queratinização 
Isto ocorreu devido à dificuldade em superpor origens histológicas tão distintas do carcinoma baso e espinocelular em uma mesma entidade ${ }^{(5)}$.

Clinicamente, pode apresentar-se como carcinoma basocelular nodular ou nódulo-ulcerativo clássico, ou pode também desenvolver-se a partir de lesão ulcerada ou mesmo esclerodermiforme. Por isto alguns autores consideram o CBE como uma variante clínica do carcinoma basocelular ${ }^{(6-7)}$. Entretanto é importante ressaltar que o BSC apresenta caráter agressivo e com alta incidência de metástases à distância, o que o difere substancialmente do carcinoma de células basais ${ }^{(8)}$.

O CBE também apresenta as mesmas características epidemiológicas do carcinoma basocelular, incidindo em áreas de exposição solar, localizando-se no segmento cefálico em $90 \%$ dos casos e atingindo preferencialmente indivíduos adultos brancos.

No início de sua evolução, devido às variações de apresentação clínica e controvérsias dos achados histológicos um erro diagnóstico pode ocorrer ${ }^{(4)}$. Quando um BSC agressivo é negligenciado ou não excisado completamente pode destruir o globo ocular, invadir a órbita, cavidade nasal e cérebro. A recorrência local deste tumor pode levar a mutilações faciais extensas conforme já relatado na literatura ${ }^{(9)}$.

A radioterapia pode ser usada como terapia adjuvante ao tratamento cirúrgico. No presente caso, o curso lento e o caráter infiltrativo da lesão associados à não adesão ao tratamento pelo paciente levaram ao quadro de pobre prognóstico.

\section{ABSTRACT}

Basosquamous carcinoma is a rare tumor with features of both basal cell and squamous cell carcinoma, linked by a transition area. It is a rare epithelial neoplasm with a tendency for local recurrence. It also has a high incidence of distant metastasis, a condition that differentiates it from the basal cell carcinoma. In this case, the slow course of the infiltrative lesion associated to patient non-compliance to treatment led to a poor prognosis.

Keywords: Basal cell carcinoma; Carcinoma, basosquamous/ diagnosis; Case reports

\section{REFERÊNCIAS}

1. Johnson BF, Moore PJ, Goepel JR, Slater DN. Basosquamous carcinoma, a wolf in sheep's clothing? Report of 3 cases. Postgrad Med J. 1989;65(768): 750-1.

2. Mitsuhashi T, Itoh T, Shimizu Y, Ban S, Ogawa F, Hirose T, Shimizu M. Squamous cell carcinoma of the skin: dual differentiations to rare basosquamous and spindle cell variants. J Cutan Pathol. 2006;33(3):246-52.

3. Martin RC $2^{\text {nd }}$, Edwards MJ, Cawte TG, Sewell CL, McMasters KM. Basosquamous carcinoma: analysis of prognostic factors influencing recurrence. Cancer. 2000;88(6):1365-9.

4. Manz D, Schmitz K, Lehnerdt G. Basosquamous carcinoma - basal cell or squamous cell carcinoma? Ger Med Sci. Meeting 2005. [76. Jahresversammlung der Deutschen Gesellschaft für Hals-Nasen-Ohren-Heilkunde, Kopf- und Hals-Chirurgie e. V.]. Available from: http://creativecommons.org/licenses/bync-nd/3.0/deed.de

5. Santos OLR, Silva SCMC, Gurgel PJC, Maceira JMP, Sodré CT, Pereira Júnior ACP. Carcinoma basoescamoso pigmentado. An Bras Dermatol. 1994; 69(1):22-6.

6. Lever WF, Schaumburg-Lever G. Histopathology of the skin. $6^{\text {th }}$ ed. Philadelphia: Lippincott; c1983.

7. Cannon CR, Hayne S. Basosquamous carcinoma of the head and neck. Ear Nose Throat J. 1990:62(12):822-4.

8. Bowman PH, Ratz JL, Knoepp TG, Barnes CJ, Finley EM. Basosquamous carcinoma. Dermatol Surg. 2003;29(8):830-2; discussion 833.

9. Rodríguez-Domínguez FJ, Hernández-Gil J, Segarra Fenoll JD, Hernández-Gil A. Carcinoma basoescamoso mutilante en región facial. An Otorrinolaringol Ibero Am. 2007;34(6):549-55. 